
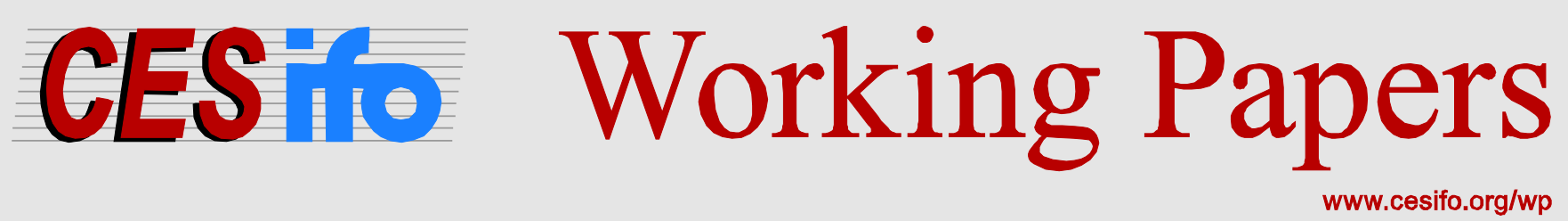

\title{
Hurricanes? Let's Make a Move
}

\author{
Nekeisha Spencer \\ Mikhail-Ann Urquhart
}

\author{
CESIFO WORKING PAPER NO. 6081 \\ CATEGORY 10: ENERGY AND ClimATE ECONOMICS \\ SEPTEMBER 2016
}

An electronic version of the paper may be downloaded

- from the SSRN website:

- from the RePEc website:

- from the CESifo website: www.SSRN.com

www.RePEc.org

www.CESifo-group.org/wp 


\title{
Hurricanes? Let’s Make a Move
}

\begin{abstract}
This paper establishes the relationship between migration and hurricanes in the Central American and Caribbean region. In contrast to previous studies, we employ hurricane destruction indices to study this relationship. These indices measure geographical destruction which gives us a more comprehensive and accurate view of damage and impact that it has on the movement of people to international destinations. Our estimates reveal that on average hurricane increases migration. We also find that the impact is greater when a hurricane hits a country directly as opposed to not making landfall. These results have policy implications for long term economic growth.
\end{abstract}

Nekeisha Spencer Economics Department University of the West Indies

Mona / Jamaica nspence3@binghamton.edu
Mikhail-Ann Urquhart

Economics Department

University of the West Indies

Mona / Jamaica

murquha1@binghamton.edu 


\section{Introduction}

Many developing countries experience a high percentage of migration to more advanced countries. This phenomenon has been particularly true for the Central American and Caribbean (CAC) region. Several factors both in the host and recipient countries drive this activity. Host countries tend to offer greater income earning opportunities serving as the primary pull factor for migrants. Past migrants also play a role in 'recruiting' and instilling the desire in people to migrate; especially the desire to live with family members who previously migrated. However, there are other factors driving individuals from their home country such as political and social instabilities which result in host countries providing asylum statuses to those seeking them. Many CAC countries are particularly vulnerable to natural disasters because of their physical characteristics and location. For the period 1989 to 2005, the EM-DAT international disaster database reports a total of 534 natural disasters that affected over 33 million people and causing at least US\$53 billion in damages across the $\mathrm{CAC}$ region ${ }^{1}$. These countries do face a lot of destruction and often times experience significant economic drain in recovering and re-developing their economies. With natural disasters exacting such a heavy toll, it is not difficult to understand why people might choose to migrate to avoid such destruction especially if the rebuilding of lives presents a challenge. Noy (2009) finds that developed countries are more resilient to the shocks of natural disasters compared to those developing. This explains the movement to more developed nations because of their capabilities to manage negative shocks and provide greater relief to people in the event that disasters occur.

The focus of this paper is to investigate the impact of hurricanes on migration from Central America and the Caribbean to the United States. Using the historical hurricane tracks housed by

\footnotetext{
${ }^{1}$ D. Guha-Sapir, R. Below, Ph. Hoyois - EM-DAT: The CRED/OFDA International Disaster Database www.emdat.be - Université Catholique de Louvain - Brussels - Belgium.
} 
the National Oceanic and Atmospheric Administration, between 1989 and 2005, there are approximately 269 storms $^{2}$ that have been recorded tracking through the location of aforementioned countries. As the tracks show, these hurricanes have been increasing in frequency and severity with more than one occurring within the same month of the same season. These storms have caused significant economic damage to these countries. Strobl (2012) reports a 0.84 percentage point reduction in GDP per capita growth resulting from hurricane striking the CAC region. Bluedorn (2005) indicates that hurricane shocks reduce output by 0.3 percentage points for the same region. These studies and the statistical estimates from EM-DAT point to the fact that the CAC countries do experience negative impacts from disasters. Although there is a strand of literature investigating the impact of natural disasters on external migration movements from developing countries (including Reuveny and Moore, 2009; Drabo and Myabe, 2015), to the best of our knowledge, there are no papers specific to the CAC region which examine the relationship between external migration and the strength of hurricanes. Given their potentially detrimental impact to the region, it is worth establishing if natural disasters, specifically hurricanes, which are more frequent than any other high impact disaster in the $\mathrm{CAC}$ region, are driving people to live in the United States. Moreover, in contrast to previous disaster-migration studies which use the number of disasters (Drabo and Myabe, 2015); the level of reoccurrences (Saldaña-Zorrilla and Sandberg, 2009); and the number of people affected (Reuveny and Moore, 2009), we utilize Strobl (2012) hurricane destruction indices which make use of historical hurricane tracks computed using geographic details at the country level to study the impact.

\footnotetext{
${ }^{2}$ For more information, see https://coast.noaa.gov/hurricanes/index.html?redirect=301 ocm
} 
In the next section, we present the disaster-migration literature. We then discuss the data and the hurricane indices, the empirical strategy and the estimated results. Lastly, we conclude with some policy implications of our results.

\section{Disaster-Migration Literature}

Understanding the Impact of Natural Disasters: Vulnerabilities and CAC

Understanding the specific impact of natural disasters is important in the context of globalization, as disasters in one region have the potential to impact international flows and relationships. A natural disaster can be defined as "the occurrence of an abnormal or infrequent hazard that impacts vulnerable communities or geographical areas, causing substantial damage, disruption and possible casualties, leaving the affected communities unable to function normally" (Benson \& Clay, 2003). Natural disasters may be hydrometeorological or geophysical. Hydrometeorological disasters include drought, floods, tropical cyclones and hurricanes, while geophysical disasters include volcanic eruptions, earthquakes, tsunamis (Benson \& Clay, 2003).

Natural disaster can significantly impact countries in various ways. At the micro-level, all types of natural disasters directly threaten the lives, properties, and livelihood of those impacted. Considering the national impacts, disasters can lead to short term decreases in gross domestic product (GDP) and in the long term can cause reduced economic growth, a reduction in investment, and redistribution of public funds (Benson \& Clay, 2003). These impacts, whether short term or long term, may act as catalyst for migration. Noy (2009) finds that specific effects of natural disasters can negatively impact GDP. In a global study of the impacts of natural disaster from 1970-2003, Noy finds that changes in GDP are specifically related to the value of damage to properties caused by natural disasters, but not by the loss of lives due to these same disasters. 
Since the 1980's there has been an increase in the number of natural disasters such storms and flooding across the globe (Renaud et al., 2007; OECD, 2003). Climate change will cause the number of disasters to continue to rise. Hurricanes that impact the CAC region are predicted to become more frequent and severe (Schmidt-Verkerk, 2012). Hurricanes have the potential to impact the livelihoods of people by way of destroying agricultural production, destroying houses, increasing the spread of diseases, and causing injury or death. Natural disasters may even lead to an increase in exposure to violence, public debt, and regional inequalities (Charvériat, 2000; Naude, 2009).

The impacts of natural disasters such as hurricanes can be severe for both developed and developing countries. Consider the cases of Hurricane Mitch in 1998 and Hurricane Katrina in 2005. Hurricane Mitch led to approximately 20,000 deaths and displaced over 2 million people in the CAC (McLeman and Hunter, 2010). Hurricane Katrina caused massive flooding in New Orelans. Hurricane Mitch in 1998 was followed by a significant increase in migration from Honduras and Nicaragua and Hurricane Katrina led migration away from New Orleans (McLeman and Hunter, 2010).

The value of disaster damages has exponentially increased over that period, with many of these damages being shouldered by developing countries (OECD, 2003). The losses caused by hurricanes are costly and appear to be increasing annually. The estimated normalized losses from damages of Hurricane Hugo in 1989 in Puerto Rico is US\$1.5 million, while the losses from Hurricane Mitch in Nicaragua, Honduras, El Salvador, and Guatamala in 1998 was reported to be up to US\$7 million (Pielke, 2003). While all countries face increasing costs associated with disasters, the poorer segments in any country are most likely to be adversely impacted by natural 
disasters (Renaud et. al, 2007). However, the impacts of natural disasters is much greater for developing countries than developing countries.

The channel of the impact of natural disasters that leads to migration may not necessary be directly through the initial or primary shocks, but rather through secondary shocks. After a natural disaster there may be secondary effects resulting from long term disruptions in segments of the economy and potential dissolution in the trust of the political and social institutions within a country (OECD, 2003). These secondary effects will likely have implications for the affected populations to obtain necessities. Thus, the impact of the disaster is less about the actual occurrence of the event and more about the vulnerabilities of those who are impacted (Grote et al., 2006).

Developing countries are particularly vulnerable to disasters due to their "colonial history, reliance on primary exports, extremes of poverty and inequality, limited physical and social infrastructure, inappropriate land use and weaknesses in governance and public administration" (Pelling \& Uitto, 2001). Additionally, developing countries face vulnerabilities associated with the exclusion of the poor and increasing population growth rates (Mechler, 2004). For instance, Noy (2009) finds that for small, developing countries, this negative relationship between the value of disaster damage and GDP is stronger than for larger developed countries.

One of the reasons developing countries face high risks associated with storms is because of their experience with rural-urban migration and urban poverty. Future predications of the impact of storms include rising sea levels, are particularly important for areas such as small islands and coastal zones. In fact, there is a relatively larger portion of the urban population of developing countries living in these vulnerable areas when compared to developed countries. Suriname, Guyana, Belize, and the Bahamas including list of top countries with urban population living in low coastal areas. Other low lying regions include northeast South America and the Caribbean, 
where $20 \%-50 \%$ of the population in many Caribbean countries live in especially low coastal zones (McGranahan et al., 2007; Sattherwaite et al. 2007). McGranahan et al. show that $13 \%$ of the population and $16 \%$ of land in small island states is in low coastal zones. Approximately $60 \%$ of the population in South America, Central America and the Caribbean live along the coastal areas.

Small islands such as those that make up the Caribbean face even more specific challenges that make them exceedingly vulnerable to the impact of natural disasters than other developing countries. Firstly, the Caribbean is prone to tropical storms which can lead to flooding. The magnitude of flooding is compounded by the rising sea level caused by climate change. Secondly, small islands tend to have small populations and economies, much experience with resource exploitation, and relatively large portions of informal structures (Sattherwaite et al. 2007). Thus, the vulnerabilities of small islands include size, insularity, environmental factors, a limited capability to mitigate disaster, demographic factors, and economic factors. This means that Caribbean states are especially vulnerable to natural disasters because of large areas of coastal zones, single urban centers, dependence on natural resources, and high transport costs. Interestingly, the "larger, and least globally connected island states are those most severely affected by disaster (Haiti, PNG, Jamaica). Although the smaller islands are the ones mostly at risk from 'knock-out' by a single event” (Pelling \& Uitto, 2001).

Using syndrome analysis, Manuel-Navarrete et al. (2007) categorize the 13 predominant symptoms of the CAC's vulnerability to hydrometeorological disasters into 3 causal patterns: 1) social organization and population dynamics, 2) disasters and environmental degradation, and 3) economic. The thirteen interdependent factors they propose as key to CAC vulnerability to disasters are "(a) poverty and socio-economic marginalization, (b) institutional and democratic 
weakness, (c) rapid, unregulated, and unplanned urbanization, (d) formation of slums and occupation of hazardous areas, (e) population growth, (f) migration from rural to urban areas, (g) increasing population affected by disasters, (h) ecosystem conversion, (i) erosion, (j) increasing intensity of hydrometeorological events causing disasters, (k) increasing economic damage due to disasters, (l) failure to communicate scientific knowledge effectively, and (m) expansion of agriculture" (Manuel-Navarrete et al. 2007).

Through the population and social dimensions, poverty and poor institutional frameworks contribute to the development of poor, informal urban communities in areas prone to landslides, sinkholes, and floods. The second pattern suggests that degradation of environment by way of practices such as deforestation, inappropriate plant farming, and overgrazing are encouraged by poverty, social marginalization, population growth and increases in agricultural production. The degradation leads to unbalance ecosystems which make the impacts of natural disasters more severe. Further, the impacts of one natural disaster can create increased risks for future disasters. The final dimension that Manuel-Navarrete et al. (2007) propose indicates that much of the damage from disasters is caused by poor housing infrastructure. This then puts additional strain on the resources due to the increased need for healthcare, the increased debt, the fall in the standard of living, and the loss of jobs. (Manuel-Navarrete et al. 2007)

\section{The Impact of Natural Disasters on Hurricanes: Exploring Previous Studies}

The question of impacts of natural disasters on migration is not clear. There are three plausible results: 1) no effect, 2) a negative effect or 3) a positive effect. It may be that residents in disaster prone areas, such as the CAC region may simply adjust their behavior so that they learn to mitigate the risks of a hurricane shock. When changes in the environment are gradual, these residents may be forced to relocate temporarily by way of internal migration, but may decide to return and rebuild 
(Tacoli, 2009; Aleexev et al. 2011). Further, governments or NGOs may have strategies to reduce the impacts of hurricanes. For example, residents in northern Bangladesh affected by a tornado in 2004 , report that there was no migration in response to the disaster because the tornado created job opportunities in addition to the fact that disaster relief was adequate and quick, and a large enough area was not impacted (Paul, 2005). Other supporters of this hypothesis may be believe that the occurrence of natural disaster are not regularly severe enough to warrant any changes in external migration. Studying the case of internal migration in Indonesia, Bohra-Mishra et al. (2014) find that sudden disasters are not likely to lead to permanent migration.

A negative relationship between the natural disasters and migration suggest that the occurrence of the natural disaster reduces the likelihood of migration. This outcome suggests that those impacted by natural disasters face financial and emotional losses, such as jobs, assets or family members that make it too difficult to face the costs and other challenges associated with migration (Alexeev et al., 2011). Yang (2008) finds that persons in rural El Salvador who lived near to a severe earthquake were less likely to have a close relative that migrated. He attributes this negative relationship to earthquake related disruptions in the methods used to finance migration. Interestingly, Yang (2008) also finds that families that experienced death in the same year of the earthquake were more likely to have relatives who migrated. Similarly, Grote et al. (2006) study the migration behavior of persons in Sri Lanka impacted by tsunami and find that people who experience loss in the form of a death or injury of a relative are less likely to migrate.

In addition to loss, disasters may lead to an increase in employment opportunities and even encourage social bonding (Paul, 2005; Tse, 2012). A case study of Indonesia found that volcanoes, floods, and earthquakes were negatively related to migration (Tse, 2012). The study further reveals 
that floods reduce the migration of entire households, while earthquake reduces split household migration.

In this study, we anticipate that the third outcome - a positive relationship between out migration and hurricanes - will be the most applicable hypothesis for the CAC. This region is susceptible to particular vulnerabilities discussed before, such as limited economic resources. The recovery from hurricanes will not be as successful as is the case in more developed and larger countries. Studies have shown that there is a positive significant relationship between natural disasters - particularly storms and flooding - and international migration. When disasters cause long lasting impacts on unemployment, migration can reduce the risk of facing future disasters. Further, it is a rational choice as the disasters deplete household resources and thus lowers the opportunity cost of moving. A study of disaster risk management in El Salvador determined that urban residents will use migration and remittances as a tool to reduce the negative impacts of natural disasters such as a loss in jobs (Wamsler, 2007).

While there is some evidence that people displaced by hurricanes are likely to return to their homes to rebuild, extreme impacts may result in migration (Tacoli, 2009). Using GMM estimates, Naude (2009) finds that a larger number of natural disaster is significantly related to an increase in net emigration in Sub Saharan Africa. Naude also finds that the occurrence natural disaster in one year relates to civil conflicts in the following year. Alexeev et al. (2011) observe weather related disasters internationally from 1986 to 2006 and find a positive and significant relationship between the number of people impacted by a disaster and the level of emigration. Barrios Puente et al. (2015) show that unusual rainfall in the Mexico is negatively relates to migration. Thus, lower than usual levels of rain (the starting condition for drought-like impacts) lead to more migration. 
Using a panel dataset, Drabo and Mbaye (2015) apply country fixed effects to estimate the impact of natural disasters on global migration rates. They find that the number of natural disasters and the intensity of natural disasters are positively and significantly related to migration rates. They find that this relationship is based on the contemporaneous and lagged impacts of hydrological and meteorological natural disasters. Further, they find evidence that the behavior patterns by region are different, where international migration seemed to be more strongly related to natural disasters for countries in the Latin American \& Caribbean regions and Europe \& Central Asia regions.

Controlling for GNP per capita, cost of migration, distance, political variables, and social variables, Reuveny and Moore (2009) report that migration is positively related to the number of people impacted by a natural disaster and the share of land dedicated to growing permanent crops, but negatively related to the arable land per capita. These results indicate that the more people are impacted by the occurrence of a disaster and the more land becomes unusable for agriculture, the greater outward migration will be. The study by Reuveny and Moore, however, does not explore whether these differences varied by region.

Examining the ten most severe storms to hit Central America and the Caribbean from 1990 to 2009, Andrade Afonso (2011) finds that being hit by one of these ten storms one year ago is related to a $16.5 \%$ increase migration to the U.S. However, it is likely that result overestimated the effect of hurricanes on migration due to the limited cases of the storms observed.

\section{Data}

This study explores the relationship between hurricanes and migration from Central America and the Caribbean to the U.S. from 1989 to 2005 for the 30 countries listed in Table 1 of the Appendix. To do this analysis we use annual data on hurricanes, migration flows to the US, population, and GDP per capita. The annual U.S. migration data comes from various years of the Statistical 
Yearbook of the Immigration and Naturalization Service and various years of the Office of Immigration Statistics' Yearbook of Immigration Statistics. The migration data measure the number of persons who obtain legal permanent resident status by country of birth in a given year. The population data is obtained from United States Census Bureau (2015) International Database. The population data was used to scale the migration flows. Thus the migration variable used measures the ratio of a country's population that obtained legal permanent status in the U.S. in any given year.

A hurricane wind damage index is used to measure the occurrence and strength of hurricanes. The index, developed by Strobl (2012) provides an estimate of wind destruction of hurricanes that pass over or nearby a country in a given year. The hurricane wind damage index is a function of the estimate of the wind velocity relative to the eye of the hurricane and weight for the particular characteristics of a location that make it susceptible to damage. The equation that Strobl (2012) use to calculate the index is

$$
W I N D_{i, r, t}=\left(\sum_{j=1}^{J} \int_{0}^{\tau} V_{j t}^{\lambda} w_{i, j, r, t} d r\right) \quad \text { if } V_{j t}>177 \mathrm{~km} / \mathrm{hr}(\mathrm{SS} \geq 3) \text { and zero otherwise. (Eqn. 1) }
$$

where $V$ is the estimate of wind speed at any point, $w$ is the weight of the potential damage based on the characteristic of the place, $j$ is a particular place, $J$ is the set of $j$ places for a given country, $i$, and $\lambda$ "the parameter that links wind speed to its level of destruction."

The limitation of the index is that it does not account for other factors associated with hurricanes such as rainfall. Also it does not include all hurricanes, just those that are relatively strong (measuring 3 or above on the Saffir-Simpson hurricane wind scale). The strength of this index is 
that provides a measurement for the potential destruction from a hurricane, which allows for a deeper understanding of the damages of these storms beyond just their occurrences.

Our control variable in the analysis is GDP per capita. Facing the difficulty to access the GDP per capita rates for all the countries in the sample for the period of interest, we use the Institute for Health Metrics and Evaluation real GDP per capita series, compiled and estimated by James et al. (2012). James et al. collect GDP per capita data from seven sources and use several regression models to estimate missing values to create a database for 210 countries from 1950 to 2015 . We specifically access the series based on real GDP per capita data collected from the World Bank, which has a base year of 2005 and is measured in U.S. dollars.

Figure 1 shows the distribution of hurricane occurrences from 1989 to 2005. Most of the CAC countries in this study experienced more than 3 hurricanes during the time period. The hurricane tracks over the same period are shown in Figure 2.

\section{Empirical Strategy}

We estimate the impact of hurricanes on migration for the countries in the $\mathrm{CAC}$ region using the following panel-country fixed effects model:

$\ln \left(\frac{\text { Mig }}{\text { Pop }}\right)_{i t}=\alpha_{1}+\alpha_{2} H_{i, t-1 \rightarrow t}+\alpha_{3} \ln (\text { Income })_{i, t-1 \rightarrow t}+\alpha_{4} \ln \left(\frac{M i g}{P o p}\right)_{i t-1}+\gamma_{t}+\delta_{i}+u_{i t} \quad$ (Eqn. 2)

where $\ln \left(\frac{M i g}{P O p}\right)$ is the $\log$ of migration per capita at time $t$ for country $i$; $H$ is our measure of hurricane destruction that is calculated over all hurricanes and all localities in each country at time $t$ and $t-1$; and ln (Income) is GDP per capita. The hurricane destruction measure is assumed to be an exogenous to the economies. In other words, the index is constructed without the use of economic data (Strobl, 2012). We include lag GDP since income is a factor that can influence an individual's decision to migrate. If income is low then residents in the home country may not be 
able to satisfy a desired way of life, and so individuals might seek to take hold of opportunities that enable one to do so. Finally, we include a time period lag of migration per capita. The logic behind this inclusion stems from the notion that having friends or family members in the USA can influence the decision to migrate. Friends or family abroad may act a pull factor to migration as they would have a foundation laid and explored available opportunities that would encourage migration. Thus this lowers the cost of migrating. Consequently, we use a one year lag to ascertain the influence of past migrants on current migration. We limit our lags to $t-1$ so as not to reduce our sample size. Additionally, we include time and country fixed effects to hold constant any peculiarities that might exist across the years and within each country.

\subsection{Robustness Checks}

To ensure that our results are robust, we construct hurricane variables based on the incidence of hurricanes. Initially, we create two dummy variables, one when a country is directly hit and one capturing an indirect hit. Countries receiving a direct hit are those in the direct path of the hurricane while those experiencing an indirect hit are those where the path of the hurricane does not make landfall. The dummy representing a direct hit $\left(H^{D}\right)$ takes a value of 1 if a hurricane made landfall and 0 otherwise; and the indirect dummy $\left(H^{I}\right)$ takes a value of 1 if a hurricane did not make landfall but passes close by (see Equation 3.) We use maps containing historical hurricane tracks ${ }^{3}$ from the National Oceanic and Atmospheric Administration (Appendix: Figure 2) to observe the path of the hurricanes for each country in our sample and associated storm reports to properly construct our dummy variables. Using the same source, we also construct a dummy variable $H^{H}$ which

\footnotetext{
${ }^{3}$ For more information, see https://coast.noaa.gov/hurricanes/index.html?redirect=3010cm
} 
indicates that whether a country was hit whether directly or indirectly. This variable mimics our initial hurricane measure where we look at the effect of a country being affected instead of separating the effects by nature of hit. Thus, $H^{H}$ is assigned a value of one if a country got struck indirectly or directly and zero otherwise (see Equation 4). Table 4 displays the results from these regressions.

$\ln \left(\frac{M i g}{P o p}\right)_{i t}=\alpha_{1}+\alpha_{2} H_{i, t-1 \rightarrow t}^{D}+\alpha_{3} H_{i, t-1 \rightarrow t}^{I}+\alpha_{4} \ln (\text { Income })_{i, t-1 \rightarrow t}+\alpha_{5} \ln \left(\frac{M i g}{P o p}\right)_{i t-1}+\gamma_{t}+\delta_{i}+u_{i t}$

(Eqn. 3)

$\ln \left(\frac{M i g}{P o p}\right)_{i t}=\alpha_{1}+\alpha_{2} H_{i, t-1 \rightarrow t}^{H}+\alpha_{3} \ln (\text { Income })_{i, t-1 \rightarrow t}+\alpha_{4} \ln \left(\frac{M i g}{P o p}\right)_{i t-1}+\gamma_{t}+\delta_{i}+u_{i t}$

(Eqn. 4)

\section{Estimated Results}

Table 2 shows the results from Equation 2. The first column lists the variables in the model. Turning our attention to the second column, we see that hurricanes do not have a contemporaneous effect on migration. This seems plausible since it is unlikely that in the year of a hurricane strike, a significant increase in migration would be observed. On the other hand, considering a one period lag - which is an indication of whether a hurricane strike has a persistent effect - we observe a significant impact on migration. Thus, an increase in the hurricane damage index by 1 is associated with a, a $6.6 \%$ increase in migration per capita. This indicates that a one year period gives people an opportunity to prepare to leave their home country. Controlling for income, our estimates suggest that current economic situation is not the driving force behind 
migration; instead, a last period's income does influence whether there is outward movement from country of origin to the USA. The estimates show that a $10 \%$ increase in income reduces migration per capita by approximately $9.2 \%$ suggesting that faced with a good economic situation, some persons might choose not to leave. Column 2 adds a one period lag for migration. This addition tells the same story as above except that an average hurricane strike increases migration by $5.1 \%$ with a $10 \%$ in current income reducing migration by only $2.5 \%$. The latter is indicates that planning to migrate is important to individuals. The estimate on lagged migration shows that if a country experienced a $10 \%$ increase in outward movements one year before then we can expect almost a $10 \%$ increase in current relocation to the USA.

Table 2: Regression of Hurricane Wind Damage Index on Migration per capita

\begin{tabular}{llll}
\hline & Model 1 & & Model 2 \\
\hline $\mathrm{H}_{\mathrm{t}}$ & -0.009 & $\mathrm{H}_{\mathrm{t}}$ & 0.005 \\
& $(0.018)$ & & $(0.016)$ \\
$\mathrm{H}_{\mathrm{t}-1}$ & 0.066 & $\mathrm{H}_{\mathrm{t}-1}$ & $0.051^{*}$ \\
& $(0.019)$ & & $(0.014)$ \\
$\ln \left(\right.$ Income $\left._{\mathrm{t}}\right)$ & -0.372 & $\ln \left(\right.$ Income $\left._{\mathrm{t}}\right)$ & $-0.025^{*}$ \\
& $(0.385)$ & & $(0.009)$ \\
$\ln \left(\right.$ Income $\left._{\mathrm{t}-1}\right)$ & $-0.924^{* *}$ & $\ln \left(\right.$ Migration $\left._{\mathrm{t}-1}\right)$ & $0.986^{*}$ \\
& $(0.396)$ & & $(0.005)$ \\
\hline Observations & 435 & & 431 \\
\hline
\end{tabular}

\subsection{Robust Results}

Table 3 presents the estimations from Equations $3 \& 4$. The first six variables in column 1 are the hurricane dummy variables which capture the occurrence of a storm. As model 3 shows, if a country is directly hit, migration per capita increases by $8.4 \%$ while given a one year lag, we see an increase by $15.4 \%$. On the other hand, there is no effect in time $t$ from an indirect hit but we observe that a one period lag increases outward movement by $8.6 \%$. These results supports the fact that hurricane strikes do not result in immediate mass movements. So initially, people do not 
leave immediately but may wait at least at least a year after following a disaster. In addition, our results suggest that a direct hit has a greater effect than an indirect hit. This is plausible since a direct hit usually brings more destruction and requires more rehabilitation which can result in a migration a year later. As with our results from Table 2, income and prior migration has the same directional relationship on current migration. Columns 3-4 shows the results from Equation 4. In model 4, which considers the fact that a country is hit whether directly or indirectly, a hurricane occurring that last period affects migration per capita, increasing it by $10.5 \%$. Like model 1 , here we see income having a similar effect but only a year later. Comparing model 5 to model 2, we see a similar impact for a lagged hurricane effect, income and migration. Our robustness checks supports our original results which indicate that hurricanes have a positive impact on migration but their effects are seen a year after the storms take place.

Table 3: Regression of Migration Per Capita on the Incidence of a Hurricane

\begin{tabular}{|c|c|c|c|}
\hline & Model 3 & Model 4 & Model 5 \\
\hline $\mathrm{H}^{\mathrm{H}}$ & & $\begin{array}{l}-0.028 \\
(0.041)\end{array}$ & $\begin{array}{l}0.046 \\
(0.041)\end{array}$ \\
\hline $\mathrm{H}_{\mathrm{t}-1}^{\mathrm{H}}$ & & $\begin{array}{l}0.105^{*} \\
(0.039)\end{array}$ & $\begin{array}{l}0.114 * \\
(0.028)\end{array}$ \\
\hline$H_{t}^{D}$ & $\begin{array}{l}0.084 * * * \\
(0.045)\end{array}$ & & \\
\hline$H_{t-1}^{D}$ & $\begin{array}{l}0.154^{*} \\
(0.057)\end{array}$ & & \\
\hline$H_{t}^{I}$ & $\begin{array}{l}0.006 \\
(0.063)\end{array}$ & & \\
\hline$H_{t-1}^{I}$ & $\begin{array}{l}0.086^{* *} \\
(0.034)\end{array}$ & & \\
\hline $\ln \left(\right.$ Income $\left._{t}\right)$ & $\begin{array}{l}-0.040^{*} \\
(0.011)\end{array}$ & $\begin{array}{l}-0.367 \\
(0.385)\end{array}$ & $\begin{array}{l}-0.035^{*} \\
(0.010)\end{array}$ \\
\hline $\ln \left(\right.$ Income $\left._{t-1}\right)$ & & $\begin{array}{l}-0.958^{* *} \\
(0.395)\end{array}$ & \\
\hline $\ln ($ Migrationt-1) & $\begin{array}{l}0.978^{*} \\
(0.005)\end{array}$ & & $\begin{array}{l}0.979 \\
(0.005)^{*}\end{array}$ \\
\hline Observations & 431 & 431 & 431 \\
\hline
\end{tabular}

\subsection{Geographical Effects}


Our discussion thus far indicates that hurricanes positively impacts on migration per capita. It is instructive to see how the effects play out in individual countries. We use model 2 to achieve this but only report the results of the lagged hurricane variable since we previously find that generally no contemporaneous effects. The results in Table 4 are only for the countries showing positive and significant effects. The estimates reveal that the Central American countries Guatemala, Nicaragua and El Salvador experience the highest migration per capita; this is true for Barbados and St. Vincent \& the Grenadines in the Caribbean region with latter having lower migration rates than the former. We can thus assume that countries in Central America are less resilient to hurricane strikes.

Table 4: Geographical Effects of Hurricanes on Migration Per Capita

\begin{tabular}{lr|lr}
\hline & & & \\
Aruba & $0.163^{* * *}$ & Guatemala & $3.45^{* * *}$ \\
& $(0.001)$ & & $(0.282)$ \\
Anguilla & $0.004^{* *}$ & Jamaica & $0.047^{* * *}$ \\
& $(0.002)$ & & $(0.001)$ \\
Netherland Antilles & $0.337^{* * *}$ & St. Kitts \& Nevis & $0.045^{* * *}$ \\
& $(0.005)$ & & $(0.0002)$ \\
Antigua \& Barbuda & $0.079^{* * *}$ & St. Lucia & $0.502^{* * *}$ \\
& $(0.002)$ & & $(0.012)$ \\
Bahamas & $0.021^{* * *}$ & Montserrat & $0.125^{* * *}$ \\
& $(0.004)$ & & $(0.004)$ \\
Belize & $0.088^{* * *}$ & Nicaragua & $3.33^{* * *}$ \\
& $(0.003)$ & & $(0.010)$ \\
Barbados & $0.808^{* * *}$ & El Salvador & $1.33^{* * *}$ \\
& $(0.022)$ & & $(0.323)$ \\
Cuba & $0.087^{* *}$ & Turks \& Caicos & $0.091^{* * *}$ \\
& $(0.037)$ & & $(0.004)$ \\
Dominica & $0.107^{* * *}$ & Trinidad \& Tobago & $0.405^{* * *}$ \\
& $(0.004)$ & St. Vincent \& & $(0.060)$ \\
Grenada & $0.277^{* * *}$ & Grenadines & \\
& $(0.022)$ & & \\
\hline
\end{tabular}




\section{Conclusion}

Natural disasters including hurricanes remain a challenge for developing countries. Those in the Latin American and Caribbean region are no exception which along with other developing countries continue to experience significant economic damage from hurricane strikes. This paper investigates the relationship between migration and hurricanes using an innovative measure of local measure of destruction at the country level which has not been employed in the literature to study the impact. Country fixed effects estimation shows that hurricanes have a positive one period lag and significant impact on migration per capita. This is line with the findings of developing country studies. In addition to what is already in the literature, we find evidence that when a hurricane directly hits a country, migration per capita is greater than if a country is hit indirectly. This is a plausible result since a direct hit brings more destruction and will likely encourage people to migrate especially those who have difficulty in recovering from such disasters. Results like these have policy implications for long term economic growth and development. For example, it is worth trying to keep individuals especially those highly educated locally since they can contribute to developing good social and economic policies to deal with certain problems that are faced on an ongoing basis. Such policies can assist countries move closer to being developed. In addition, having a capable workforce in all industries is necessary for productivity which often leads to economic growth of economies. 


\section{References}

Alexeev, A., Good, D. H., \& Reuveny, R. (2011). Weather-related disasters and international migration. Draft, Indiana University

Andrade Afonso, Onelica C. (2011). Originally published in Explorations: The UC Davis Undergraduate Research Journal, Vol. 14.

Barrios Puente, G., Perez, F. and Gitter, R. J. (2015). The effect of rainfall on migration from Mexico to the U.S. International Migration Review. doi: 10.1111/imre.12116.

Benson, C., \& Clay, E. (2003). Economic and financial impacts of natural disasters: An assessment of their effects and options for mitigation: Synthesis report. London: Overseas Development Institute, May.

Bohra-Mishra, P., Oppenheimer, M., \& Hsiang, S. M. (2014). Nonlinear permanent migration response to climatic variations but minimal response to disasters. Proceedings of the National Academy of Sciences, 201317166.

Bluedorn, J.C. (2005). Hurricanes: Intertemporal Trade and Capital Shocks. Nuffield College Economics Paper 2005-W22.

Charvériat, C. (2000). Natural disasters in Latin America and the Caribbean: An overview of risk. Inter-American Development Bank, Research Department Working papers series; 434.

Drabo, A., \& Mbaye, L. M. (2015). Natural Disasters, migration and education: An empirical analysis in developing countries. Environment and Development Economics, 20(6), 767-796.

Grote, U., Engel, S., \& Schraven, B. (2006). Migration due to the tsunami in Sri Lanka:

analyzing vulnerability and migration at the household level (No. 106). ZEF discussion papers on development policy.

James, S. L., Gubbins, P., Murray, C. J., \& Gakidou, E. (2012). Developing a comprehensive time series of GDP per capita for 210 countries from 1950 to 2015. Population Health Metrics, $10(1), 12$.

Manuel-Navarrete, D., Gomez, J. J., \& Gallopín, G. (2007). Syndromes of sustainability of development for assessing the vulnerability of coupled human-environmental systems. The case of hydrometeorological disasters in Central America and the Caribbean. Global Environmental Change, 17(2), 207-217.

McGranahan, G., Balk, D., \& Anderson, B. (2007). The rising tide: assessing the risks of climate change and human settlements in low elevation coastal zones. Environment and urbanization, 19(1), 17-37.

McLeman, R. A., \& Hunter, L. M. (2010). Migration in the context of vulnerability and adaptation to climate change: insights from analogues. Wiley Interdisciplinary Reviews: Climate Change, 1(3), 450-461. 
Mechler, R. (2004). Natural disaster risk management and financing disaster losses in developing countries (Vol. 1). Verlag Versicherungswirtsch. Retrieved from http://www2.cepal.org.mx/www3/iadb-eclac-project/pdf/meschler2003.pdf, December 18, 2015. National Oceanic and Atmospheric Administration (n.d). Historical Hurricane Tracks. Retrieved from https://coast.noaa.gov/hurricanes/index.html?redirect=301 ocm, December 12, 2015.

Naudé, W. (2009). Natural disasters and international migration from Sub-Saharan Africa. Migration Letters, 6(2), 165-176.

Noy, Ilan (2009). The macroeconomic consequences of natural disasters. Journal of Development Economics, 88, 221-231.

OECD (2003). Emerging Systemic Risks in the 21st Century: An Agenda for Action, OECD Publications Service, France. Retrieved from http://www.oecd.org/futures/globalprospects/37944611.pdf, December 18, 2015.

Paul, B. K. (2005). Evidence against disaster-induced migration: the 2004 tornado in northcentral Bangladesh. Disasters, 29(4), 370-385.

Pelling, M., \& Uitto, J. I. (2001). Small island developing states: natural disaster vulnerability and global change. Global Environmental Change Part B: Environmental Hazards, 3(2), 49-62.

Pielke Jr, R. A., Rubiera, J., Landsea, C., Fernández, M. L., \& Klein, R. (2003). Hurricane vulnerability in Latin America and the Caribbean: Normalized damage and loss potentials. Natural Hazards Review.

Renaud, F., Bogardi, J. J., Dun, O., \& Warner, K. (2007). Control, adapt or flee: How to face environmental migration? UNU-EHS.

Reuveny, Rafael and Will H. Moore (2009), Does Environmental Degradation Influence Migration? Emigration to Developed Countries in the Late 1980s and 1990s. Social Science Quarterly, 90:3.

Saldaña-Zorrilla, S. O., \& Sandberg, K. (2009). Spatial econometric model of natural disaster impacts on human migration in vulnerable regions of Mexico. Disasters, 33(4), 591-607.

Satterthwaite, D., Saleemul Huq, Mark Pelling, Hannah Reid and Patricia Romero Lankao. (2007). Adapting to climate change in urban areas: The possibilities and constraints in low-and middle-income nations Vol. 1. Iied.

Schmidt-Verkerk, K. (2012). The potential influence of climate change on migratory behaviour-a study of drought, hurricanes and migration in Mexico. Doctoral dissertation, University of Sussex.

Strobl, E. (2012). The economic growth impact of natural disasters in developing countries: Evidence from hurricane strikes in the Central American and Caribbean regions. Journal of Development Economics, 97(1), 130-141. 
Tacoli, C. (2009). Crisis or adaptation? Migration and climate change in a context of high mobility. Environment and Urbanization, 21(2), 513-525.

Tse, C. W. (2012). Do Natural Disasters Lead to More Migration? Evidence from Indonesia Retrieved from https://cream.conferenceservices.net/resources/952/3365/pdf/MGDNF2013_0075.pdf, December 21, 2015.

United States Census Bureau (2015). International Database. Retrieved from https://www.census.gov/population/international/data/idb/informationGateway.php, December 19, 2015.

Wamsler, C. (2007). Bridging the gaps: Stakeholder-based strategies for risk reduction and financing for the urban poor. Environment and Urbanization, 19(1), 115-142.

Yang, D. (2008). Risk, migration, and rural financial markets: Evidence from earthquakes in El Salvador. Social Research, 955-992. 


\section{Appendix}

Table 1: List of Countries Included in the Analysis

\begin{tabular}{ll}
\hline & \\
Anguilla & Haiti \\
Antigua And Barbuda & Honduras \\
Aruba & Jamaica \\
Bahamas & Martinique \\
Barbados & Mexico \\
Belize & Netherlands Antilles \\
Cayman Islands & Nicaragua \\
Costa Rica & Panama \\
Cuba & Puerto Rico \\
Dominica & Saint Kitts And Nevis \\
Dominican Republic & Saint Lucia \\
El Salvador & Saint Vincent And The Grenadines \\
Grenada & Trinidad And Tobago \\
Guadeloupe & Turks And Caicos Islands \\
Guatemala & Virgin Islands \\
& \\
\hline
\end{tabular}


Figure 1 Number of Hurricane Hits by Country from 1989-2005

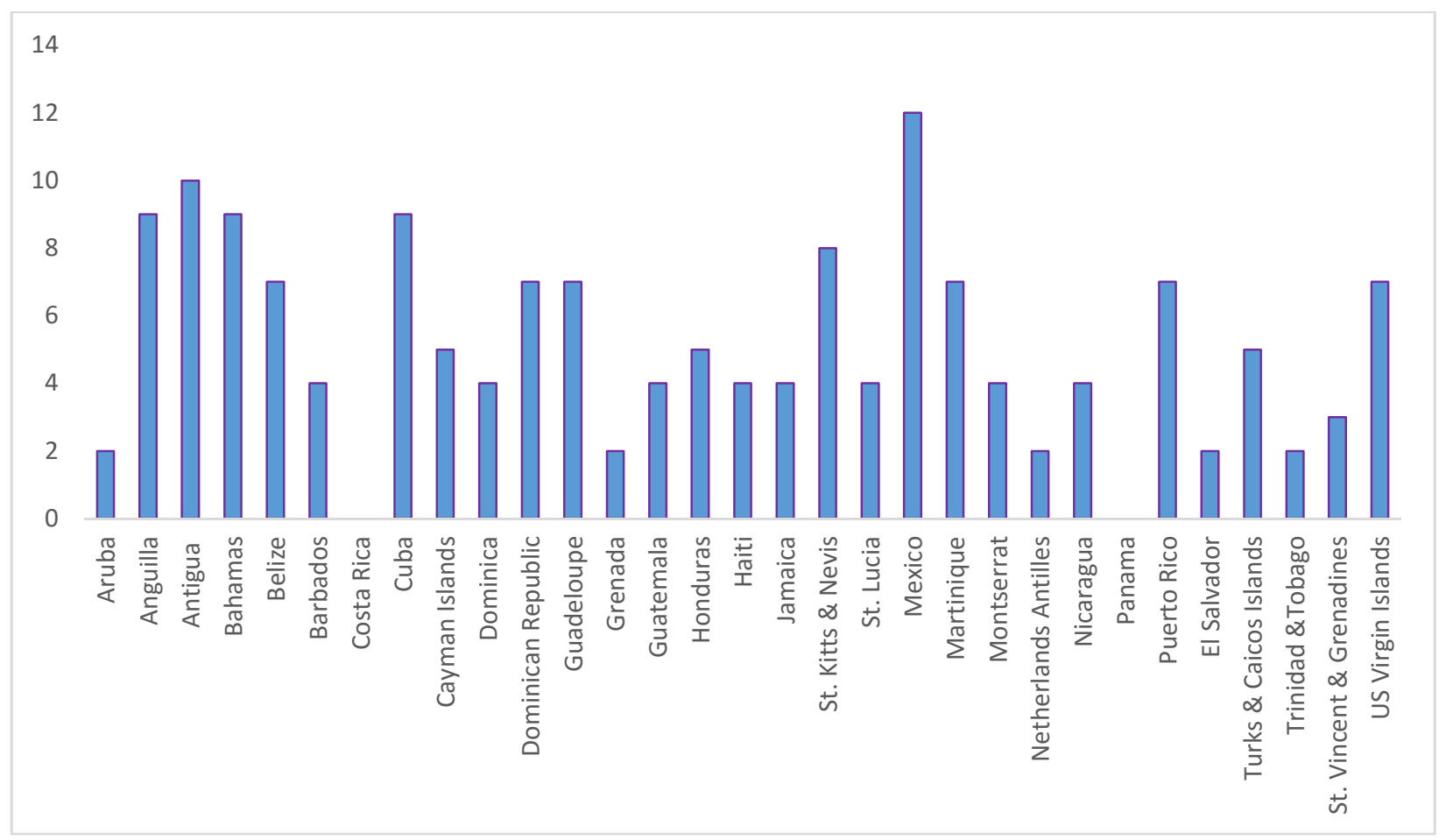


Figure 2: Historical Hurricane Tracks (1989 to 2005) for All Categories of Hurricanes

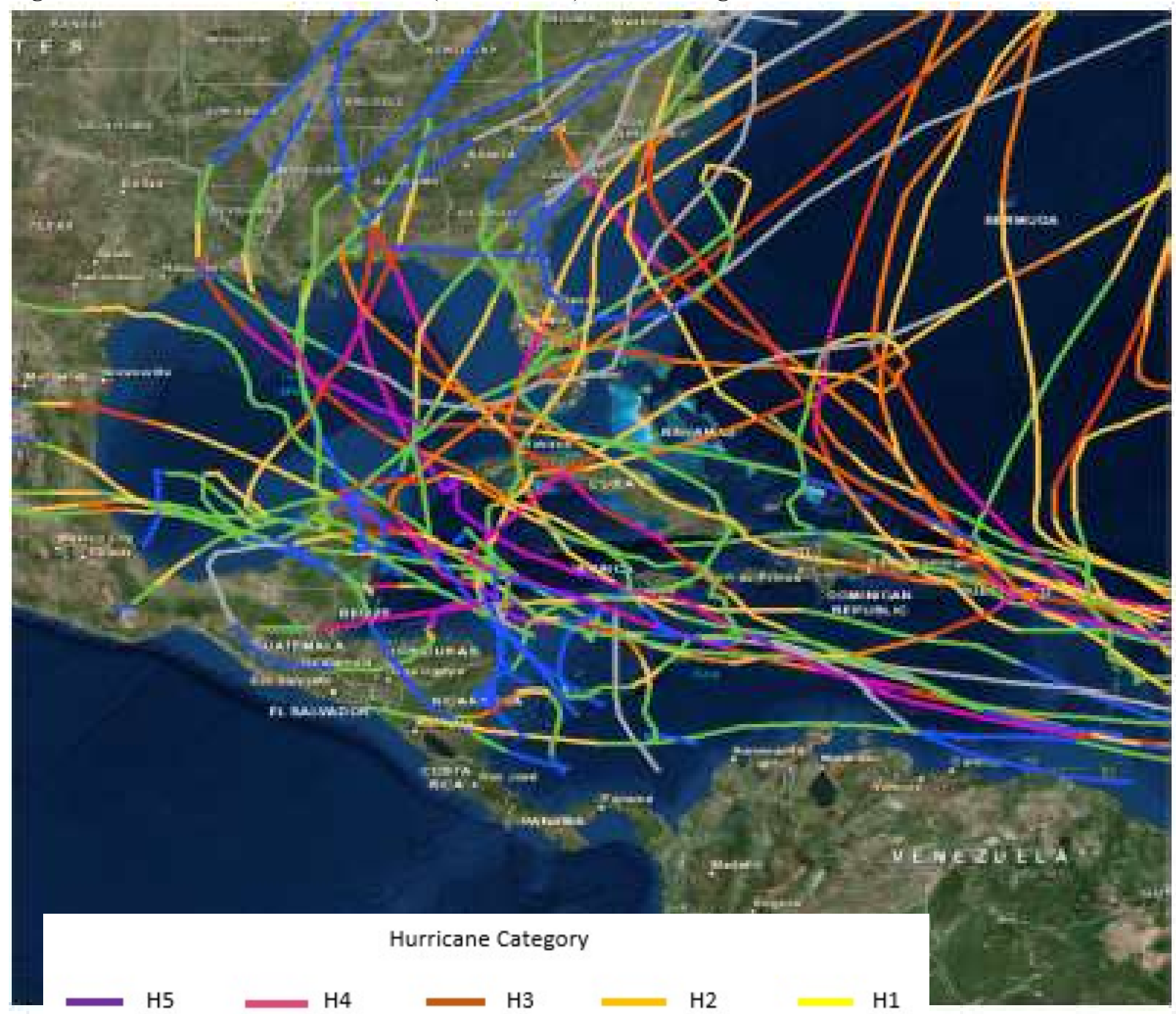

Source: NOAA https://coast.noaa.gov/hurricanes/index.html?redirect=301ocm 